\title{
COMPOSITIONAL ANALYSIS OF THE HUITZILA AND LA LOBERA OBSIDIAN SOURCES IN THE SOUTHERN SIERRA MADRE OCCIDENTAL, MEXICO
}

\author{
J. A. DARLING, F. M. HAYASHIDA \\ Museum of Anthropology, University of Michigan, Ann Arbor, MI 48109 (USA)
}

(Received March 1. 1995)

\begin{abstract}
Results of neutron activation analysis of 100 obsidian specimens from the southern Sierra Madre Occidental are discussed. Two separate peralkaline sources are identified, Huitzila and La Lobera, which are chemically and spatially distinct. Subsequent subdivision of each source into spatial and compositional subgroups suggest separate flows or subsources. Identification of archaeological artifacts which match these sources compositionally suggests that Huitzila and La Lobera were important sources of high quality obsidian which was distributed widely in northern Mesoamerica.
\end{abstract}

Source characterization is a necessary first step in the reconstruction of ancient patterns of exploitation and distribution of obsidian or volcanic glass by humans. Many studies have used compositional analysis as an effective means of artifact source description and comparison. Obsidian sources are generally treated as compositionally homogeneous since numerous studies have revealed that chemical variation between sources or flows is significantly greater than variation within flows, especially for flows with different geological or formational histories. ${ }^{1-4}$ This forms the basis of the familiar "provenience postulate" for sourcing archaeological artifacts. $^{5}$

From 1991-1993, field surveys and geologic sampling were conducted in the region of the southern Sierra Madre Occidental in the states of Durango, Zacatecas, and Jalisco, Mexico to investigate three previously unexamined obsidian source areas. ${ }^{6}$ These are Huitzila-La Lobera, Llano Grande, and Nochistlán (Fig. 1). Source characterization has been undertaken as part of a general study of obsidian utilization, distribution and exchange in prehispanic Zacatecas. In this paper we present a discussion of compositional variability noted for the Huitzila-La Lobera source area and consider implications for geological and archaeological interpretation.

Overview of Regional Geology: The Sierra Madre Occidental dominates north and northwest Mexico covering an area of $296,000 \mathrm{~km}^{2}$ and is comprised predominantly of rhyolitic ash-flow tuffs and silicic lava dating from 34 to $23 \mathrm{Ma}^{7-10}$ The obsidian sources of the Huitzila - La Lobera region are situated at the southern terminus of this physiographic province where it intersects the Trans-Mexican Neovolcanic belt of 'more recent Plio-pleistocene age. Dramatic changes in topography and volcanism in this area are the result of the unique tectonic and volcanic boundaries which encompass the intersection of the older Basin and Range province with the recent features of the Neovolcanic belt, and the tectonic boundary of the Jalisco block and North American plate. ${ }^{10}$

Recent studies in this complex region have outlined a geologic sequence beginning with the early Miocene Sierra Madre Ashflows dating from 22-27 Ma followed by somewhat more recent activity at the Cerro San Vicente shield volcano $22 \mathrm{Ma}$ (Teul basaltic andesite). Even 


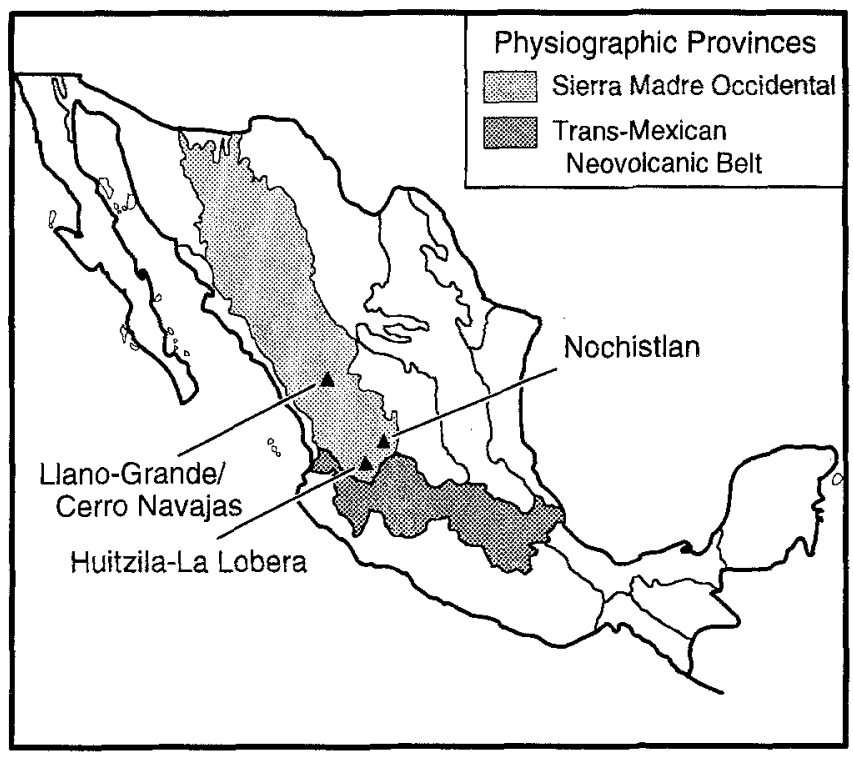

Fig. 1. Index Map of Mexico showing the physiographic provinces and obsidian source areas mentioned in the text

more recent Miocene activity is marked by the appearance of the San Cristobal Basalts (alkali olivine basalts, basaltic andesites) dating 10 to $11 \mathrm{Ma}$ based on samples from a volcano near García de La Cadena and in the Canyon of the Río Santiago (Fig. 2). ${ }^{10}$

The volcanic glass deposits of Huitzila-La Lobera, west of Garcia de la Cadena, appear to overlie the earlier Sierra Madre formation and probably originate in the later Miocene phase. Other nearby sources of volcanic glass have been identified both to the south and to the east of the Huitzila region. However, the sources to the south, including the Tequila Volcano and the Sierra la Primavera near Guadalajara, are associated with more recent volcanic activity. To the east of Huitzila, highly weathered and possibly older deposits of volcanic glass near Nochistlán may correspond to earlier Miocene formations of the Sierra Madre Occidental.

Qualitative differences in obsidian raw material sources are related to their geology and geomorphology and will influence their exploitation by humans. These differences can include raw material abundance, nodule size, fracture quality, inclusion and color. ${ }^{6,11,12}$ Aging through weathering and devitrification will also reduce the utility of raw obsidian for certain production techniques, such as prismatic blade production. This is true of the obsidian flows of Nochistlán which are lower in quality for certain kinds of production, whereas the larger younger sources of the Neovolcanic chain generally yield higher quality raw material. ${ }^{13}$

Sources of high quality raw material are more likely to be exploited and both finished and unfinished artifacts will have a wider distribution from the source. As has been pointed out by WEIGAND ${ }^{12}$, younger and higher quality sources in the Sierra Madre Occidental and the Neovolcanic chain to the south may constitute rare resources among older and/or lower quality sources. ${ }^{12}$ Thus the distribution of high quality sources will have an impact on human use and exchange of both unworked obsidian and finished objects in northern Mexico. The potentially younger, high quality deposits from the Huitzila-La Lobera region represent one such northern rare resource which was used locally and possibly traded to other areas. 


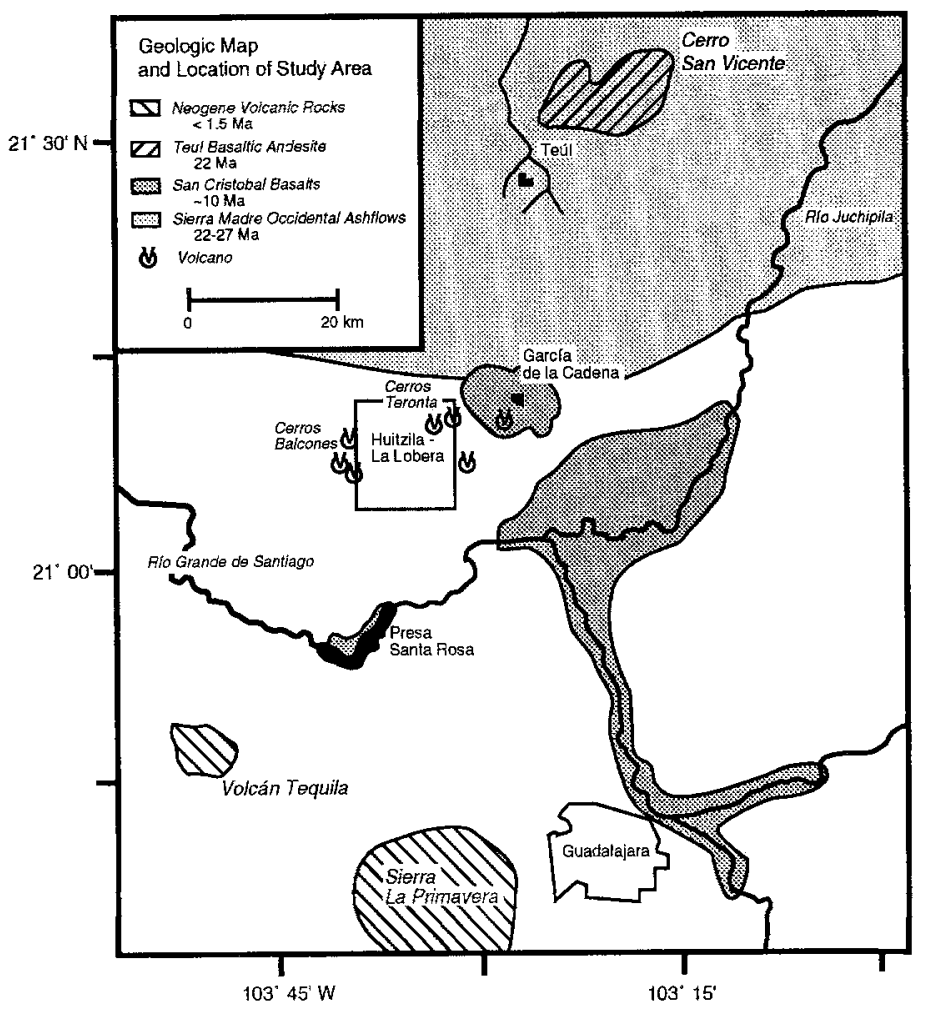

Fig. 2. Location of the Huitzila and La Lobera obsidian sources in relation to dated volcanic deposits. Map adapted from MOORE et al. ${ }^{10}$

\section{Experimental}

Following the identification of the La Lobera-Huitzila source in 1991, intensive field surveys were conducted in 1992 to determine the areal extent, the character of deposits, and the presence of prehistoric quarrying. Selection of material for compositional analysis was made to include a sample representing the range of variation at the source. Recommended sample size for source characterization varies in the literature from 30 to as many as 100 specimens and depends on the variability of the natural deposits. ${ }^{3,14}$ In our case, 100 specimens were selected from 33 collection locations (out of a total 50 areas sampled) arranged in a rough north-south transect following the road connecting the town of Huitzila, Zacatecas to La Lobera, Jalisco in the South. Due to the structure of our survey the western extent of obsidian deposits has not yet been determined and east-west variability has not yet been studied.

Only natural unmodified material was collected for source characterization. The geological samples include whole or partial nodules, mainly fist-size, from both natural outcrops and prehistoric extraction sites. Each sample was carefully recorded in its natural context and 
located using the Universal Transmercator Grid or UTM coordinates. Obsidian which varied from the more common black flow-banded type by color, size or density was purposively collected to obtain an adequate representation of variability in physical characteristics.

A program of chemical characterization and analysis of geological and archaeological obsidian from northern and northwest Mexico is currently underway. This includes highprecision trace element characterization of source samples and artifacts using instrumental neutron activation analysis (INAA). All of the analyses are being performed at the Ford Nuclear Reactor, Phoenix Memorial Laboratory of the University of Michigan, Ann Arbor (PML), and the Missouri University Research Reactor Center (MURR), Columbia, Missouri. Samples of identical source material are being analyzed at both reactor facilities to (1) enhance resolution of elements and chemical patterns and (2) provide data for interlaboratory comparisons to facilitate normalization of results between these two facilities.

Results of interlaboratory comparisons including analyses performed at PML will be reported separately. The data reported in this paper will be confined to INAA performed at MURR in the archaeometry program under the direction of Michael Glascock and Hector Neff. Summaries of specific procedures and methodology used at MURR for INAA of archaeological materials and data reduction are available in literature published previously., ${ }^{3,15}$

\section{Results and Discussion}

General physical and geographic characteristics of the Huitzila-La Lobera region have been described in an earlier publication. ${ }^{6}$ In brief, field surveys have identified a broad region of weathered and broken volcanic glass deposits and outcrops encompassing an area of more than

Table 1

Mean elemental concentrations in parts per million measured by INAA at MURR

\begin{tabular}{cccc}
\hline ELEMENT & $\begin{array}{c}\text { HUTZILA- LA LOBERA } \\
\mathbf{n}=\mathbf{1 0 0}\end{array}$ & $\begin{array}{c}\text { HUTZRA } \\
\mathbf{n}=\mathbf{6 4}\end{array}$ & $\begin{array}{c}\text { (GROUP A-B) } \\
\mathbf{n}=\mathbf{3 6}\end{array}$ \\
\hline $\mathrm{La}$ & $68.2 \pm 12.5$ & $77.3 \pm 3.2$ & $51.9 \pm 0.9$ \\
$\mathrm{Lu}$ & $0.993 \pm 0.082$ & $1.05 \pm 0.02$ & $0.888 \pm 0.025$ \\
$\mathrm{Nd}$ & $55.0 \pm 10.9$ & $62.7 \pm 4.1$ & $41.3 \pm 1.6$ \\
$\mathrm{Sm}$ & $11.6 \pm 1.8$ & $12.9 \pm 0.5$ & $9.22 \pm 0.38$ \\
$\mathrm{U}$ & $3.74 \pm 0.57$ & $3.46 \pm 0.17$ & $4.24 \pm 0.69$ \\
$\mathrm{Yb}$ & $6.79 \pm 0.68$ & $7.27 \pm 0.26$ & $5.95 \pm 0.26$ \\
$\mathrm{Ce}$ & $136 \pm 24$ & $154 \pm 4$ & $104 \pm 2$ \\
$\mathrm{Cs}$ & $2.86 \pm 0.44$ & $2.54 \pm 0.04$ & $3.44 \pm 0.06$ \\
$\mathrm{Eu}$ & $0.219 \pm 0.049$ & $0.183 \pm 0.004$ & $0.284 \pm 0.006$ \\
$\mathrm{Fe}(\%)$ & $1.57 \pm 0.15$ & $1.68 \pm 0.02$ & $1.37 \pm 0.04$ \\
$\mathrm{Hf}$ & $14.5 \pm 1.3$ & $15.4 \pm 0.4$ & $12.9 \pm 0.3$ \\
$\mathrm{Rb}$ & $136 \pm 10$ & $128 \pm 2$ & $149 \pm 3$ \\
$\mathrm{Sb}$ & $0.422 \pm 0.045$ & $0.403 \pm 0.031$ & $0.456 \pm 0.047$ \\
$\mathrm{Sc}$ & $1.02 \pm 0.33$ & $0.785 \pm 0.031$ & $1.43 \pm 0.20$ \\
$\mathrm{Ta}$ & $3.04 \pm 0.21$ & $3.19 \pm 0.05$ & $2.77 \pm 0.06$ \\
$\mathrm{~Tb}$ & $1.70 \pm 0.20$ & $1.84 \pm 0.05$ & $1.44 \pm 0.04$ \\
$\mathrm{~Tb}$ & $14.9 \pm 1.0$ & $14.2 \pm 0.2$ & $16.3 \pm 0.3$ \\
$\mathrm{Zn}$ & $108 \pm 9$ & $113 \pm 5$ & $98.4 \pm 7.3$ \\
$\mathrm{Zr}$ & $521 \pm 64$ & $568 \pm 14$ & $439 \pm 13$ \\
$\mathrm{Cl}$ & $764 \pm 104$ & $716 \pm 78$ & $850 \pm 88$ \\
$\mathrm{Dy}$ & $10.8 \pm 1.3$ & $11.6 \pm 0.5$ & $9.20 \pm 0.58$ \\
$\mathrm{~K}(\%)$ & $3.69 \pm 0.21$ & $3.76 \pm 0.17$ & $3.56 \pm 0.21$ \\
$\mathrm{Mn}$ & $416 \pm 27$ & $425 \pm 26$ & $401 \pm 23$ \\
$\mathrm{Na}(\%)$ & $3.42 \pm 0.05$ & $3.40 \pm 0.04$ & $3.46 \pm 0.04$ \\
\hline & & &
\end{tabular}




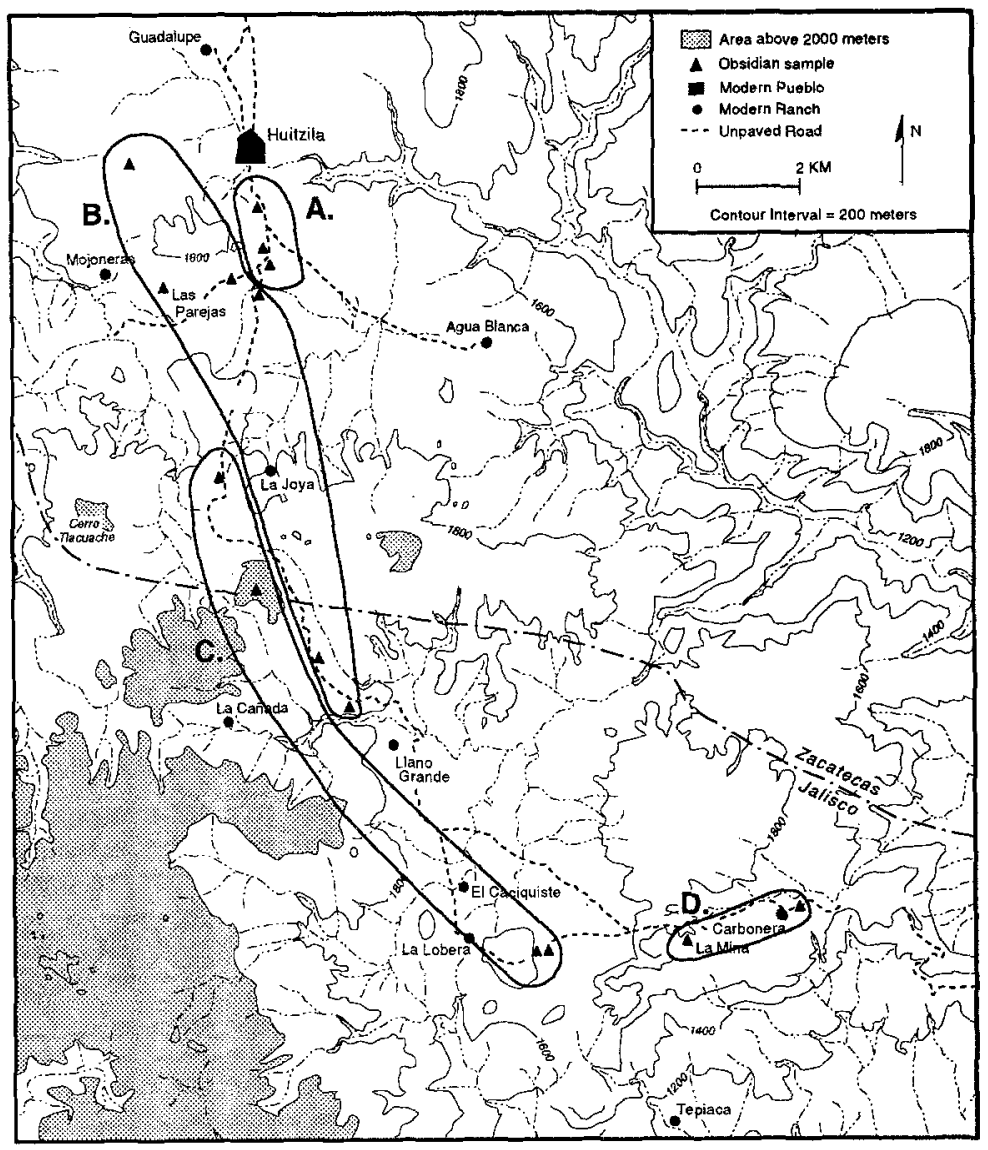

Fig. 3. Location of the Huitzila (Group A-B) and La Lobera (Group C-D) sources. Filled triangles indicate only those samples which were examined using INAA

$450 \mathrm{~km}^{2}$. Prehistoric exploitation consists of small-scale mining or harvesting of obsidian nodules from outcrops and gravel exposures. Obsidian working includes raw material testing, core preparation, decortication and the production of bifacial blanks (rough-outs).

Analysis of obsidian samples obtained from the Huitzila-La Lobera source region indicates high intrasource variability in both color and composition (see Table 1 for a summary of elements examined and their concentrations by group). Simple examination of bivariate scatterplots of trace-element concentrations from Huitzila-La Lobera demonstrates this variability. Most of the variability observed indicates a geographic separation of Huitzila-La Lobera into two groups (A-B and C-D) located northwest and southeast of each other (Fig. 3). This separation is presented in the bivariate plots of $\mathrm{Eu}$ and $\mathrm{Mn}$ and $\mathrm{Zr}$ and $\mathrm{Rb}$ (Fig. 4).

Groups A-B and C-D, or Huitzila and La Lobera, can each be subdivided into two subgroups indicative of a second level of separation. This level is represented best by bivariate plots of trace element concentrations which have been shown to correlate strongly with each other. These pairs include $\mathrm{Fe}$ and $\mathrm{Sc}, \mathrm{Fe}$ and $\mathrm{Th}, \mathrm{Th}$ and $\mathrm{Hf}, \mathrm{Cs}$ and $\mathrm{Rb}$, and $\mathrm{Fe}$ and $\mathrm{Cs}$ among 
others. $^{1,2,14}$ As is clear from the bivariate plots of these pairs the stronger, more general, separation between Huitzila and La Lobera prevails across the finer distinctions based on these elements (Fig. 5)
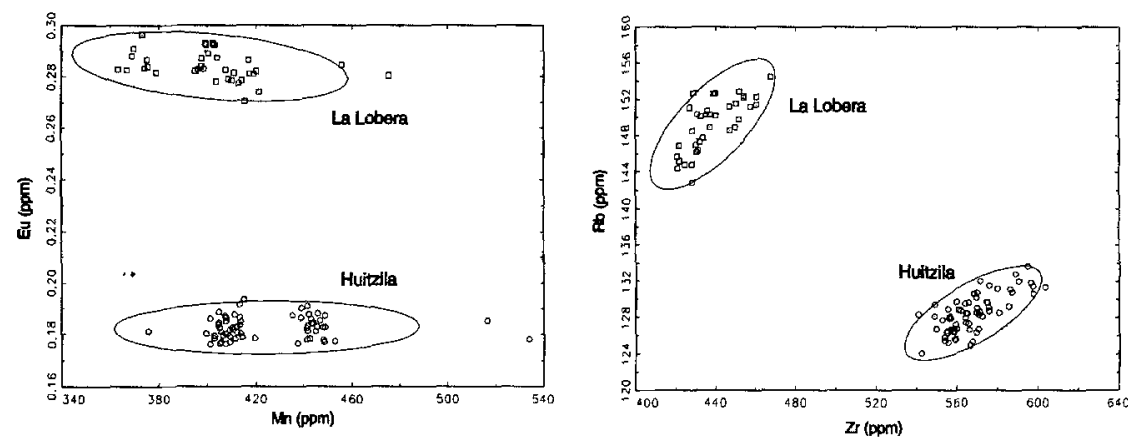

Fig. 4: Bivariate plots of $\mathrm{Mn}$ versus Eu and $\mathrm{Zr}$ versus $\mathrm{Rb}$ in parts per million for the compositional groups, La Lobera and Huitzila. Groups are indicated by probability ellipses at the $95 \%$ confidence level
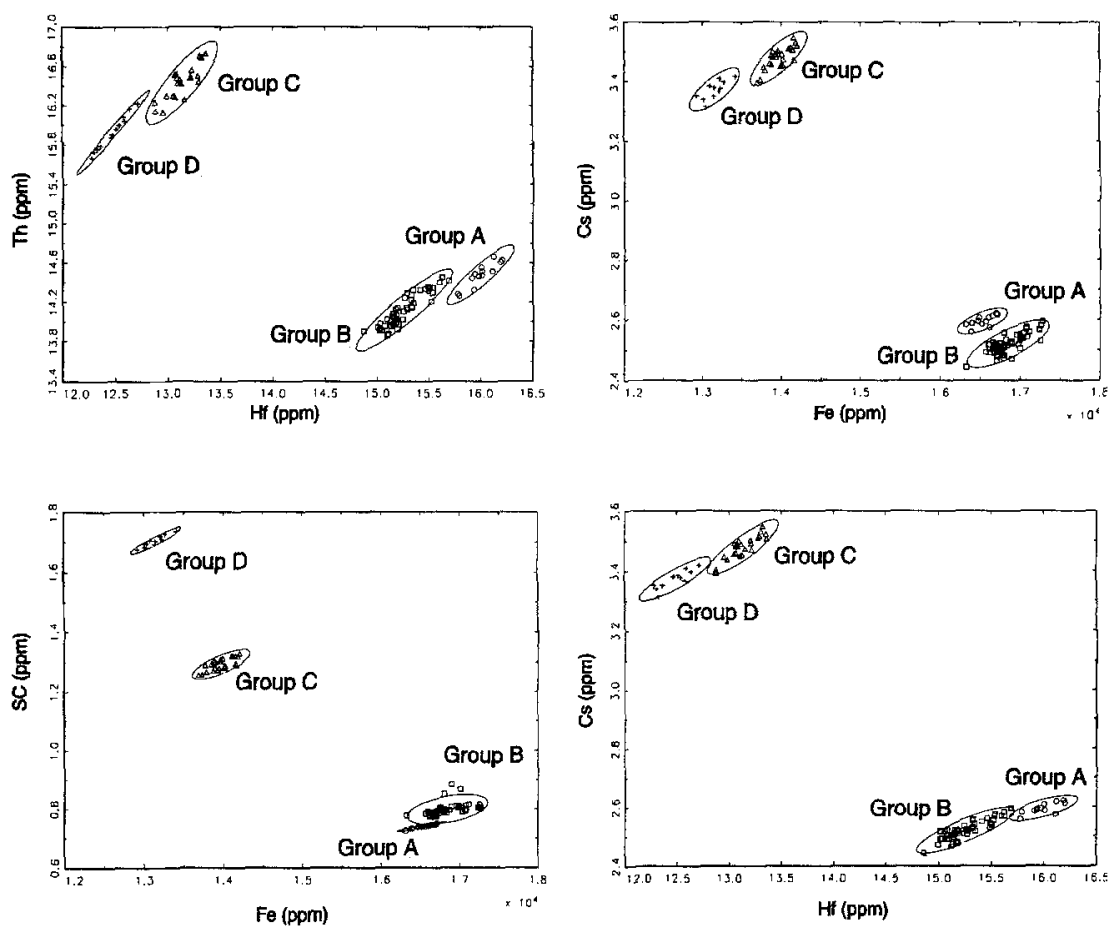

Fig. 5: Bivariate plots of correlated elements, $\mathrm{Hf}$ versus Th, Fe versus $\mathrm{Cs}$, Fe versus $\mathrm{Sc}$, and $\mathrm{Hf}$ versus $\mathrm{Cs}$, in parts per million for the compositional groups A, B, C, and D. Groups are indicated by probability ellipses at the $95 \%$ confidence level 
Interpretations: Compositionally, Huitzila and La Lobera are peralkaline (having high $\mathrm{Fe}$ and low Sc concentrations and $\mathrm{Zr}>400 \mathrm{ppm}$, see Table 1) and can be classified with the large chemical "macrogroup" of peralkaline sources associated with the Mexican Neovolcanic Belt. ${ }^{15,16}$ Other occurrences of peralkaline obsidian include sources in Hidalgo, Queretaro, and Guanajuato. In West Mexico, peralkaline volcanism is well-documented and has been associated with the extensional tectonics of the region. Peralkaline obsidian has been identified in the volcanic deposits of the Sierra La Primavera, the Volcán Tequila in Jalisco, and the Volcán Las Navajas in Nayarit. ${ }^{4-18}$ The occurrence of peralkaline obsidian in Huitzila and La Lobera suggests that these deposits may be chemically associated with the peralkaline rhyolites found to the south. This association may include the volcanism which produced the $11 \mathrm{Ma}$ San Cristobal Basalts identified at García de la Cadena by MOORE et al. ${ }^{10}$

On the basis of observed chemical variability in the analyzed samples, we propose that Huitzila and La Lobera are two separate sources, each corresponding to neighboring enuptive centers composed of at least 2 separate flows. These eruptive centers may include the small Cerros Teronta and Cerros Balcones volcanoes known to exist to the east and west of the obsidian deposits (refer to Fig. 2). Spatially this is indicated by the physical overlap or abutment of La Lobera Flow C over or against the southwestern margin of Huitzila Flow. B. This arrangement suggests stratigraphic layering of separate flows coming from different directions and separate points of origin (Fig. 3).

Within-source heterogeneity is indicated by the separation of both Huitzila and La Lobera into two spatial and chemical subgroups potentially corresponding to flows. MAHOOD ${ }^{4}$ has observed that source heterogeneity may be caused by (1) magmatic mixing or (2) temporal variations in lava flow composition originating from the same eruptive center. Temporal variations are larger in scale and MAHOOD has determined that they best account for between-flow variability at the nearby Sierra La Primavera source in Jalisco. It seems reasonable that separations based on correlated elements such as those distinguishing Groups $\mathrm{A}$ and $\mathrm{B}$, and Groups $\mathrm{C}$ and $\mathrm{D}$ may represent distinct, relatively homogeneous flows produced by the same eruptive center at different times.

Magmatic mixing should not be ruled out as a source of within-flow or intra-group variability at Huitzila and La Lobera. Defined as outcrop-scale heterogeneity which occurs when magmas of two different compositions mix prior to or during eruption, magmatic mixing may be visually identified as mingling of colors and variability in phenocryst abundance. ${ }^{4}$ Variable color characterizes many outcrops in the Huitzila-La Lobera region. One expectation of magmatic mixing might be compositional inhomogeneity indicative of outcrops of different or mixed magmatic origins. However, this is not the case for Huitzila-La Lobera in general. Bivariate plots of samples of different color from Huitzila and La Lobera demonstrate that color differences for opaque greens and reds or browns, and light gray or gray-blue are indistinguishable for the elements considered in this paper. A recent report of analyses by GLASCOCK et al. ${ }^{19}$ for red or mahogany obsidian (obsidiana "meca") presents similar findings. Rather than reflecting differences in elemental composition, color is attributed instead to differing oxidation states of iron minerals which vary with localized environmental conditions at the time of formation. ${ }^{19}$

A second type of coloration is iridescence or sheen. The iridescent obsidian of Mina La Lobera is unusual for its distinctive banded colors. Unlike differences in oxidation states, this effect is thought to be caused by high densities of micro-crystalline inclusions which occur in differing structures and orientations. Crystalline inclusions may include hedenbergite, anothorclase, and magnetite. ${ }^{20}$ Yet, iridescent color still appears to be independent of trace element composition and is a result of the physical presence and distribution of crystalline inclusions in the flow which are compositionally very similar to the obsidian matrix itself.

Conclusions: Recognition of variation within sources has fostered hierarchical classification schemes for the description and systematic analysis of natural occurrences of obsidian to 
interpret both geological and cultural patterns. ${ }^{3,21,22}$ One scheme proposed by Hurtado de Mendoza and Jester consists of four levels of increasing discrimination beginning with the source system followed by the source subsystem, the locality complex and finally the locality. ${ }^{21}$ Based in part on clustering trace-element characteristics within and among various systems and subsystems, these levels represent both natural and cultural processes, including "drift" (both human and natural), which may influence the deposition of obsidian source material prior to sampling. We propose that while these levels may be obscured slightly by human transport or other natural processes they represent natural entities including groups of lava flows, individual flows, and locations within those flows. Float obsidian or large secondary deposits are sources with very different depositional histories and should be identified and described separately in order to isolate potential chemical and physical patterns unlike those of the parent material.

In summary, Huitzila and La Lobera belong to the group of peralkaline obsidian sources in West Mexico which are associated with volcanism beginning as early as $11 \mathrm{Ma}$. We propose separating the Huitzila-La Lobera region into two sources corresponding to the Huitzila and La Lobera groups which we predict are linked to two distinct eruptive centers. The four groups, A, B, C, and D, represent subsources tentatively defined as separate flows within the Huitzila and $\mathrm{La}$ Lobera sources. These distinctions are based on groupings observed in bivariate plots of compositional data obtained from the INAA of geological samples. Color variation including iridescence does not appear to be distinguishable compositionally for the elements or trace elements observed.

Studies are currently underway to examine the distribution of obsidian from Huitzila-La Lobera and other sources of obsidian in northern Mexico as a means of examining questions of exchange and socio-political interaction among the prehispanic cultures of north and northwest Mexico, the Mesoamerican frontier, and the Central Mexican Highlands. Recently published INAA data by TROMBOLD et al. ${ }^{16}$ point toward the wide distribution of Huitzila-La Lobera obsidian at archaeological sites. Bivariate plots indicate the clear matching of four artifacts in their sample: two from the Malpaso Valley (Huitzila Group A and La Lobera Group C), one from the site of Totoate in the Bolaños Valley (La Lobera Group C) and one from the site of Las Ventanas in the Juchipila Valley (La Lobera Group C, Fig. 6). Although preliminary, the

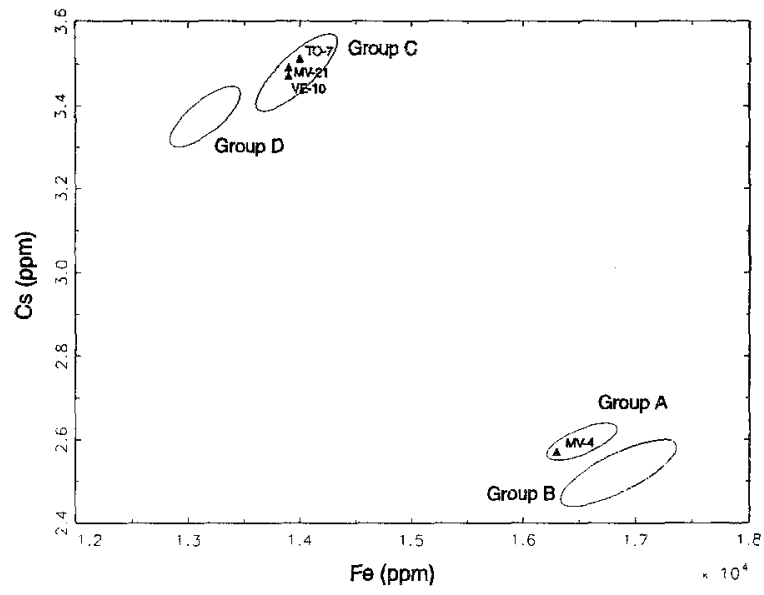

Fig. 6. Bivariate plot for $\mathrm{Fe}$ versus $\mathrm{Cs}$ in parts per million for obsidian artifacts (solid triangles) identified by TROMBOLD et $\mathrm{al}^{16}$ and the compositional groups A, B, C, and D (95\% confidence ellipses). Three clear matches with the La Lobera Group $\mathrm{C}$ and one with Huitzila Group $\mathrm{A}$ are indicated 
spatial distribution of sourced artifacts and their corresponding archaeological sites delineates an arc from N-NW to E-SE of their source with a radius of $400 \mathrm{~km}^{16}$

In conclusion, clear documentation of compositional patterning of natural glass deposits is an essential requirement for accurately matching obsidian artifacts to sources and even to individual flows. ${ }^{2}$ Other physical characteristics such as texture, fracture, density, color and phenocryst abundance also vary in obsidian sources particularly Huitzila and La Lobera, and may be useful in artifact sorting or for within-source proveniencing in combination with chemical data. In this way, intra-source patterns of material extraction at a particular source or series of outcrops over time may be linked to information on the long-range distribution of raw material, and the control of resources and exchange. By combining a variety of methods including activation analysis with observations of color, quality and fracture, we will expand our understanding of the regional distribution and organization of raw material extraction and enhance our ability to source archaeological artifacts.

Funding for fieldwork and analysis from 1991-3 was provided by various organizations of the University of Michigan including the Phoenix Memorial Laboratory (PML), the Rackham School of Graduate Studies, the Museum of Anthropology James B. Griffin Fund, and the Department of Anthropology. Additional support was provided by the Wenner-Gren Foundation for Anthropological Research, and the J. William Fulbright Program. INAA conducted at the Missouri University Research Reactor Center (MURR) was performed with the assistance of a grant from the National Science Foundation (NSF DBS91-02016). We appreciate the support of the Pre-Columbian Studies Program of Dumbarton Oaks, Washington, D.C. which provided access to their research facilities during the completion of this manuscript. Also, special thanks go to Dale Newbury and Eric Steele at the National Institute of Standards and Technology for analysis of the iridescent obsidian. All aspects of this study were conducted with the permission of the national archaeological council of the Instituto Nacional de Antropologia e Historia (INAH), Mexico. We appreciate the support of the archaeologists of the regional center of INAH, Zacatecas, during all stages of this work. Finally, we would like to acknowledge Richard Diehl, Rebecca Lange and two anonymous readers for their comments.

\section{References}

1. H. BOWMAN, F. ASARO, I. PERLMAN, J. Geol., 81 (1973) 312.

2. H. BOWMAN, F. ASARO, I. PERLMAN, Archaeometry, 15 (1973) 123.

3. M.D. GLASCOCK, G.E. BRASWELL, R.H. COBEAN, in M.S. SHACKLEY (ed) Method and Theory in Archaeological Volcanic Glass Studies, (Forthcoming).

4. G. MAHOOD, in C.W. MEIGHAN, J.L. SCALISE (eds) Obsidian Dates IV: A Compendium of the Obsidian Hydration Determinations Made at the UCLA Obsidian Hydration Laboratory, (1988) 105.

5. P.C. WEIGAND, G. HARBOTTLE, E.B. SAYRE, in T.K. EARLE, J.E. ERICSON (eds) Exchange Systems in Prehistory (1977) 15.

6. J.A. DARLING, Ancient Mesoamerica 4 (1993) 245.

7. F.W. MCDOWELL, S.E. CLABAUGH, Geol. Soc. Am. Spec. Paper 180 (1979).

8. F.W. MCDOWELL, R.P. KEIZER, Geol. Soc. Am. Bull. 88 (1977) 1479.

9. D.J. MORAN-ZENTENO, Geología de la República Mexicana (1990).

10. G. MOORE, C. MARONE, I.S.E. CARMICHAEL, P. RENNE, Geol. Soc. Am. Bull. 106 (1994) 383.

11. P.C. WEIGAND, in P.C. WEIGAND, G. GWYNNE (eds) Mining and Mining Techniques in Ancient Mesoamerica, (1982) I.

12. P.C. WEIGAND, in P.C. WEIGAND, G. GWYNNE (eds) Mining and Mining Techniques in Ancient Mesoamerica, (1982) 87

13. A. PASTRANA, in F. SODI MIRANDA (ed) Mesoamérica y Norte de México, Siglo IX-XII, (1990) 391.

14. M. NIEVENS, G. HARBOTTLE, J.B. KIMBERLIN, in M. GAXIOLA, J.E. CLARK (eds) La Obsidiana en Mesoamérica, (1989) 51. 
15. R.H. COBEAN, J.R. VOGT, M.D. GLASCOCK, T.L. STOCKER, Latin Am. Antiquity, 2 (1991) 69.

16. C.D. TROMBOLD, J.F. LUHR, T. HASENAKA, M.D. GLASCOCK, Ancient Mesoamerica, 4 (1993) 255.

17. G.A. MAHOOD, C.M. GLBERT, I.S.E. CARMICHAEL, J. Volcanology Geothermal Research, 25 (1985) 259.

18. S.A. NELSON, J. HEGRE, Bull. Volcanology, 52 (1990) 186.

19. M.D. GLASCOCK, H. NEFF, J. GARCIA-BARCENA, A. PASTRANA, Trace, 25 (1994) 66.

20. D. NEWBURY, E. STEELE, Report 837-27-94, National Institute of Standards and Technology (1994).

21. L. HURTADO DE MENDOZA, W.A. JESTER, Am. Antiquity, 43 (1978) 424.

22. J. MICHELS, J. Arch. Science, 9 (1982) 113. 